\section{Bivirkninger ved bruk av antikoagulasjonsmidler i 2013-15}

ORIGINALARTIKKEL

\section{ANNE KATRINE EEK}

E-post: Anne.katrine.eek@ous-hf.no

RELIS Sør-Øst

Avdeling for farmakologi

Laboratorieklinikken

Oslo universitetssykehus

Hun har bidratt med datainnhenting og -bearbeiding, presentasjon av resultater og artikkelskriving. Anne Katrine Eek er cand.pharm. med videreutdanning i klinisk farmasi. Hun er rådgiver og arbeider mye med antikoagulasjonsmidler.

Forfatter har fylt ut ICMJE-skjemaet og oppgir ingen interessekonflikter.

\section{BJ $\varnothing R N$ ODDVAR STR $\varnothing M$}

Område for legemiddeltilgang

Statens legemiddelverk

Han har bidratt med datainnhenting og -bearbeiding, presentasjon av resultater og artikkelskriving. Bjørn Oddvar Strøm er cand.pharm., ph.d. og er utreder innen legemiddeltilgang.

Forfatter har fylt ut ICMJE-skjemaet og oppgir følgende interessekonflikter: Han har arbeidet med bivirkningsrapportering for Bayer, som markedsfører rivaroksoban.

\section{GINE BAKKEHØI}

Statens legemiddelverk

*Nåværende adresse:

Novartis Norge

Hun har bidratt med datahåndtering og revisjon av artikkelen.

Gine Bakkehøi er cand.pharm. og Qualified Person ved Novartis Norge. Hun var tidligere seniorrådgiver ved Statens legemiddelverk.

Forfatter har fylt ut ICMJE-skjemaet og oppgir ingen interessekonflikter ut over at hun arbeider i Novartis Norge.

\section{HANNE STENBERG-NILSEN}

\section{RELIS Sør-Øst}

Avdeling for farmakologi

Laboratorieklinikken

Oslo universitetssykehus

Hun har bidratt med datainnhenting og -bearbeiding, presentasjon av resultater og artikkelskriving. Hanne Stenberg-Nilsen er cand.pharm. og spesialrådgiver med særlig ansvar for bivirkningsarbeidet og vurdering av spontanrapporterte bivirkninger. Hun har medvirket til utvikling av skjemaet for innhenting av tilleggsopplysninger.

Forfatter har fylt ut ICMJE-skjemaet og oppgir ingen interessekonflikter. 


\section{BAKGRUNN}

Hensikten med studien var å få bedre innsikt i bivirkningsprofilene til de nye direktevirkende orale antikoagulasjonsmidlene (DOAK).

\section{MATERIALE OG METODE}

Alle bivirkningsmeldinger for warfarin, dabigatran, rivaroksaban og apiksaban meldt til RELIS i perioden juni 2013-mai 2015 ble gjennomgått.

\section{RESULTATER}

Om lag 65000 personer brukte direktevirkende orale antikoagulasjonsmidler og 80 ooo warfarin i studieperioden. I studien inngikk totalt 409 bivirkningsmeldinger. $55 \%$ av meldingene gjaldt menn. I $76 \%$ av meldingene for direktevirkende orale antikoagulasjonsmidler og i $85 \%$ for warfarin var pasientene over 70 år. De vanligste bivirkningene var blødninger ( $48 \%$ for direktevirkende orale antikoagulasjonsmidler og $75 \%$ for warfarin), hvorav flest hjerneblødninger ( 91 for direktevirkende orale antikoagulasjonsmidler og 92 for warfarin). Blodpropp (terapisvikt), kognitiv påvirkning, hodepine og håravfall var noen av de øvrige bivirkningene. Det var høyest komorbiditet blant pasientene som døde. Antall meldte dødsfall var høyest for rivaroksaban (1,1 døde/1 ooo brukere) med synkende forekomst for henholdsvis apiksaban (o,9\%), dabigatran $(0,7 \%)$ og warfarin $(0,6 \%)$. Det var ulik rapporteringsgrad for preparatene, og spontanrapporteringssystemet kan derfor ikke brukes til å sammenligne legemidlers bivirkningsforekomst.

\section{FORTOLKNING}

Det forekommer bivirkninger, også alvorlige, ved bruk av alle antikoagulasjonsmidlene. Faktorer som kan gi økt risiko for bivirkninger, er høy alder, høy komorbiditet, redusert nyrefunksjon og kombinasjon av flere legemidler.

I mange år har warfarin vært enerådende i Norge som peroralt legemiddel ved behov for antikoagulasjon. Siden 2012 har imidlertid flere nye preparater blitt tatt i bruk: dabigatran, rivaroksaban, apiksaban og edoksaban. Etter at de nye antikoagulasjonsmidlene -

direktevirkende orale antikoagulantia (DOAK) - ble godkjent for refusjon på blå resept, har bruken av dem stadig økt. Etter hvert har disse også erstattet warfarin (figur 1a). Dabigatran er en direkte trombinhemmer, mens rivaroksaban, apiksaban og edoksaban er faktor Xahemmere. Edoksaban ble markedsført etter datainnsamlingen og er derfor ikke med i analysen.

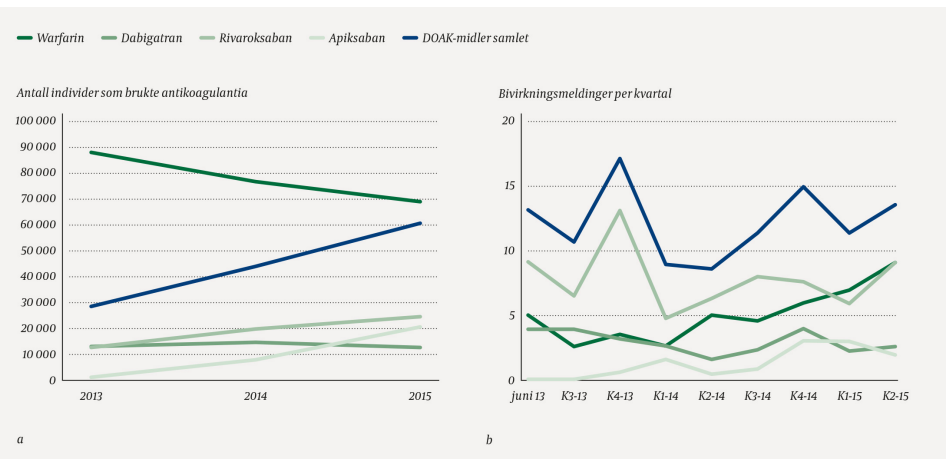

Figur 1 a) Antall unike individer som brukte direktevirkende orale antikoagulasjonsmidler (DOAK) per hele år for perioden 2013-15. Kilde: Reseptregisteret. b) Antall bivirkningsmeldinger per kvartal (K). Angitt tall er månedlig gjennomsnitt per kvartal. Kilde: Bivirkningsdatabasen

Før markedsføringstillatelse ble gitt, viste store multisenterstudier (1-3), kjent som henholdsvis RE-LY (dabigatran), ROCKET AF (rivaroksaban) og ARISTOTLE (apiksaban), at 
disse medikamentene var like gode som warfarin for å forebygge hjerneslag. Sammenlignet med warfarin reduserte de også forekomst av intrakraniale blødninger. Legemidlene forebygger også dyp venetrombose og lungeemboli (4). Sammenlignet med warfarin skulle de nye midlene være enklere å dosere, gi færre interaksjoner og regelmessig monitorering med blodprøver skulle ikke være nødvendig.

Helsedirektoratet og Statens legemiddelverk har laget retningslinjer for bruk av de nye antikoagulasjonsmidlene (5).

\section{Spontanrapportering av bivirkninger}

Pasienter som deltar i kliniske studier skiller seg på mange måter fra pasienter i en vanlig klinisk behandlingssituasjon. Derfor er det viktig å overvåke legemidlenes effekt og sikkerhet, også etter at de har fått markedsføringstillatelse. Som en del av myndighetenes legemiddelovervåking inngår spontanrapporteringssystemet der helsepersonell og pasienter, på mistanke, kan rapportere alle typer bivirkninger som oppstår ved vanlig klinisk bruk av legemidler. Fordelen med metoden er at den kan fange opp signaler om alvorlige, spesielle og/eller ukjente reaksjoner på legemidler. Disse kan så undersøkes nærmere og eventuelt bekreftes. En ulempe er at mange meldepliktige hendelser, også alvorlige, ikke rapporteres. (Bivirkninger defineres som alvorlige hvis de er dødelige, livstruende, krever/forlenger sykehusinnleggelse, medfører vedvarende/betydelig nedsatt funksjonsevne/arbeidsuførhet eller medfødt anomali/fødselsdefekt. I tillegg kan reaksjonen i seg selv medføre at hendelsen klassifiseres som alvorlig(6)).

På grunn av underrapportering kan spontanrapportering ikke brukes alene til å beregne hyppighet av en gitt bivirkning. Videre er det ulik rapporteringsgrad for forskjellige preparater. For eksempel meldes bivirkninger hyppigere for nye preparater enn for gamle. Spontanrapporteringssystemet kan derfor ikke brukes til å sammenligne ulike legemidlers bivirkningsforekomst $(7,8)$.

\section{Erfaring med warfarin}

Warfarin har vært det legemidlet med flest meldinger om alvorlige og fatale bivirkninger i Norge (9). Behandling med warfarin kan være komplisert, blant annet på grunn av smalt terapeutisk vindu. Meldte bivirkninger av warfarin er hovedsakelig blødninger. I et norsk arbeid ble 713 blødningsbivirkninger i forbindelse med bruk av warfarin undersøkt. Blødningene var relatert til høy INR, og de forekom i starten av behandlingen. Hjerneblødninger var rapportert i over halvparten av tilfellene, fulgt av gastrointestinale blødninger og andre blødninger samlet i én gruppe. $53 \%$ av hendelsene var fatale. Som tiltak for å redusere antall blødningsbivirkninger anbefalte forfatterne lavere dosering initialt, tettere kontroller og INR-verdier i nedre del av anbefalt nivå (10).

\section{Erfaring med de nye midlene}

Sjeldne bivirkninger fanges ofte ikke opp i kliniske studier som gjøres før godkjenning av nye legemidler. Noen ganger feilbedømmes hyppigheten av bivirkninger som kan skyldes få eksponerte eller et snevert utvalg av pasienter (7).

Etter markedsføringen av dabigatran, rivaroksaban og apiksaban ønsket Statens legemiddelverk og RELIS (regionale legemiddelinformasjonssentre) økt kunnskap om bivirkninger av de nye legemidlene. Helsepersonell ble oppfordret til å melde alle hendelser knyttet til mistenkte bivirkninger ved bruk av antikoagulantia samt å rapportere opplysninger om sykehistorie og annen legemiddelbruk i et eget tilleggsskjema.

Hensikten med studien var å få bedre innsikt i bivirkningsprofilene til de nye antikoagulasjonsmidlene. 


\section{Materiale og metoder}

\section{DATAMATERIALET}

Data ble samlet fra alle rapporter i den norske bivirkningsdatabasen for warfarin, dabigatran, rivaroksaban og apiksaban i prosjektperioden (1.6.2013-31.5.2015). Et skjema for å innhente tilleggsopplysninger om sykehistorie og legemiddelbruk ble sendt til alle meldere i samme periode. Oppfølging for å øke svarprosenten ble ikke foretatt. Opplysninger fra disse skjemaene ble inkludert i datamaterialet. Kun meldinger fra helsepersonell til RELIS-sentrene ble inkludert. Innmelding og registrering av bivirkninger er basert på de felleseuropeiske kriteriene for bivirkninger (6), men de aller fleste meldingene oppfylte også de smalere bivirkningskriteriene til Verdens helseorganisasjon (WHO) (11).

Bivirkningsrapportene er i databasen kun tilgjengelige i anonymisert form, men inneholder informasjon om pasientenes alder og kjønn, og det er ikke mulig å identifisere enkeltpasienter ut ifra dette. Data for antall brukere av de aktuelle legemidlene i den aktuelle perioden sammen med enkelte pasientkarakteristika (aldersintervall og kjønn) ble hentet fra Reseptregisteret. Disse dataene er ikke personidentifiserbare.

\section{REGISTRERING AV MELDINGER}

Bakgrunnsdata for alle identifiserte meldinger ble gjennomgått av minst én av forfatterne. Det ble registrert demografiske parametere (alder, kjønn), meldingenes alvorlighetsgrad, legemiddelbruk, mistenkte bivirkninger og eventuelle risikofaktorer for bivirkninger ved bruk av antikoagulantia (tabell 1-4, se også appendiks for fullstendig variabelliste). Den norske bivirkningsdatabasen har funksjonalitet for å håndtere duplikater, og duplikater var fjernet før dataanalysen.

\section{FORBRUKSDATA}

Antall brukere av de fire legemidlene ble sammen med enkelte pasientkarakteristika (aldersintervall og kjønn) hentet fra Reseptregisteret for studieperioden. Forbrukstallene er angitt som totale antall brukere av hvert legemiddel i henholdsvis 2013, 2014 og 2015.

\section{ANALYSE}

Informasjon fra de registrerte meldingene ble samlet i et regneark i Excel og analysert deskriptivt med tanke på alder og kjønn, samtidig legemiddelbruk, bivirkningshendelser og risikofaktorer for bivirkninger. Siden spontanrapporterte bivirkningsdata ikke er et representativt utvalg av alle bivirkninger som forekommer, og det er ulik rapporteringsgrad for de ulike legemidlene, ble det kun gjort deskriptiv statistikk og ikke statistiske tester.

\section{Resultater}

\section{ANTALL BRUKERE OG BIVIRKNINGER}

Uttrekk fra Reseptregisteret i prosjektperioden viste at antall brukere av direktevirkende orale antikoagulasjonsmidler og warfarin var henholdsvis 65 ooo og 80 ooo. Kjønn- og aldersfordeling fremgår av tabell 1. I perioden økte antall pasienter som fikk forskrevet direktevirkende orale antikoagulasjonsmidler, mens brukere av warfarin sank (figur 1a).

\section{Tabell 1}

Deskriptive data for pasientpopulasjon og bivirkningsmeldinger. Data for tid mellom oppstart og hendelsen er kun beregnet for den gruppen hvor oppstartstidspunkt var kjent. 
DOAK = direktevirkende orale antikoagulasjonsmidler. Kilde: Reseptregisteret og Bivirkningsdatabasen

\begin{tabular}{|c|c|c|c|c|}
\hline & \multicolumn{3}{|c|}{ Dabigatran Rivaroksaban Apiksaban } & \multirow{2}{*}{$\begin{array}{c}\text { Warfarin } \\
81097\end{array}$} \\
\hline $\begin{array}{l}\text { Totalt antall brukere av } \\
\text { antikoagulantia }\end{array}$ & 19164 & 28243 & 15290 & \\
\hline Antall meldinger & 73 & 184 & 34 & 118 \\
\hline $\begin{array}{l}\text { Antall meldinger/1000 } \\
\text { antikoagulantiabrukere }\end{array}$ & 3,8 & 6,5 & 2,2 & 1,3 \\
\hline $\begin{array}{l}\text { Andel menn blant brukere av } \\
\text { antikoagulantia (\%) }\end{array}$ & 60 & 55 & 53 & 60 \\
\hline Andel menn i meldingene (\%) & 57 & 48 & 53 & 66 \\
\hline $\begin{array}{l}\text { Andel meldinger med tilleggsskjema } \\
\text { (\%) }\end{array}$ & 48 & 53 & 44 & 33 \\
\hline Bivirkning oppstått første måned (\%) & 24 & 34 & 20 & 2 \\
\hline Bivirkning oppstått første 6 md (\%) & 55 & 73 & 75 & 11 \\
\hline Andel av pasientene 70 år og eldre: & & DOAK & & Warfarin \\
\hline Andel i bivirkningsmeldingene (\%) & & 76 & & 85 \\
\hline $\begin{array}{l}\text { Andel i hele pasientpopulasjonen med } \\
\text { antikoagulantia (\%) }\end{array}$ & & 58 & & 65 \\
\hline
\end{tabular}

${ }^{1}$ Data er hentet fra Reseptregisteret, øvrige data er hentet fra bivirkningsdatabasen

Det totale antallet bivirkningsmeldinger var 409 (291 for direktevirkende orale antikoagulasjonsmidler og 118 for warfarin). Rapporteringen $\emptyset$ kte for begge typer antikoagulantia i perioden (figur 1b). Antall bivirkningsmeldinger per 1 ooo brukere av antikoagulantia var høyest for rivaroksaban ( 6,5 meldinger $/ 1$ ooo brukere), noe lavere for dabigatran (3,8\%) og apiksaban (2,2\%) og markant lavere for warfarin $(1,3 \%)(\operatorname{tab} 1)$.

De hyppigst rapporterte bivirkningene var hjerneblødninger, blødninger i hud/muskel/ledd/slimhinner og gastrointestinale blødninger. Samtlige rapporterte bivirkninger er angitt i tabell 2. En mindre andel pasienter hadde bivirkninger i første behandlingsmåned, mens de fleste hendelsene oppsto i løpet av de første seks månedene $(\operatorname{tab} 1)$.

\section{Tabell 2}

Antall og typer av bivirkninger meldt til RELIS for de ulike legemidlene i perioden 1. juni 2013-31. mai 2015. Tallene er oppgitt som rene tall og er ikke justert for antall brukere. Kilde: Bivirkningsdatabasen

\begin{tabular}{|lcccrc|}
\hline & Dabigatran Rivaroksaban Apiksaban Warfarin Totalt \\
\hline Hjerneblødning & 14 & 63 & 14 & 92 & 183 \\
\hline Hud/muskel/ledd/slimhinne-blødninger & 13 & 41 & 2 & 7 & 63 \\
\hline Gastrointestinalblødning & 16 & 18 & 5 & 10 & 49 \\
\hline Hemoglobinfall/anemi & 11 & 19 & 3 & 5 & 38 \\
\hline Fall/traume & 1 & 10 & 3 & 11 & 25 \\
\hline Terapisvikt & 5 & 15 & 2 & 1 & 23 \\
\hline Ulcus, epigastrisk smerte & 12 & 4 & 0 & 1 & 17 \\
\hline Trombose & 2 & 11 & 2 & 1 & 16 \\
\hline Utslett/kløe & 3 & 9 & 2 & 2 & 16 \\
\hline Hjerneinfarkt & 4 & 6 & 2 & 2 & 14 \\
\hline Kognitiv påvirkning & 2 & 10 & 0 & 1 & 13 \\
\hline Leverpåvirkning & 5 & 4 & 1 & 0 & 10 \\
\hline Hodepine & 1 & 6 & 2 & 0 & 9 \\
\hline INR-økning & 0 & 0 & 0 & 9 & 9 \\
\hline Svimmelhet & 1 & 7 & 0 & 1 & 9 \\
\hline Rektalblødning & 3 & 3 & 1 & 1 & 8 \\
\hline
\end{tabular}




\begin{tabular}{|lccccc|}
\hline & Dabigatran Rivaroksaban Apiksaban Warfarin Totalt \\
\hline Postoperativ blødning & 0 & 5 & 1 & 0 & 6 \\
\hline Dyspné & 0 & 5 & 0 & 0 & 5 \\
\hline Redusert nyrefunksjon & 2 & 2 & 1 & 0 & 5 \\
\hline Håravfall & 1 & 2 & 0 & 1 & 4 \\
\hline Perifer nervepåvirkning & 2 & 2 & 0 & 0 & 4 \\
\hline Interstitiell lungesykdom & 1 & 2 & 0 & 0 & 3 \\
\hline Utløst arytmi & 1 & 2 & 0 & 0 & 3 \\
\hline Nyreblødning & 1 & 0 & 0 & 0 & 1 \\
\hline
\end{tabular}

Indikasjonen for antikoagulasjon var atrieflimmer i 304 (74\%) av bivirkningsmeldingene, mens i 69 (17\%) var indikasjonen dyp venetrombose eller lungeemboli. Dette størrelsesforholdet stemmer med forbruksmønsteret for antikoagulantia i Norge (12). I de resterende meldingene var andre indikasjoner angitt.

Tilleggsskjemaene ble fylt ut for 33 \% av warfarinbivirkningsmeldingene og for 51 \% av DOAKmeldingene (totalt 187 skjemaer).

\section{KJØNN OG ALDER}

Flere meldinger gjaldt menn enn kvinner, bortsett fra for rivaroksaban, der $48 \%$ av meldingene gjaldt menn. I DOAK-gruppen var $76 \%$ av pasientene i bivirkningsrapportene 70 år og eldre, mens tilsvarende tall for warfarin var $85 \%$. I hele den behandlede populasjonen var $58 \%$ i DOAK-gruppen 70 år og eldre, mens dette gjaldt $65 \%$ i warfaringruppen. Gjennomsnittsalderen for alle pasientene i bivirkningsrapportene var 75-8o år, mens gjennomsnittsalderen for de som døde var 79-81 år ( tab 3).

\section{Tabell 3}

Beskrivelse av dødelige hendelser. Data for tid mellom oppstart og hendelsen er kun beregnet for den gruppen hvor oppstartstidspunkt var kjent. Tallene er oppgitt som rene tall og er ikke justert for antall brukere. Kilde: Reseptregisteret og Bivirkningsdatabasen

\begin{tabular}{|lcccc|}
\hline & \multicolumn{5}{c|}{ Dabigatran Rivaroksaban Apiksaban Warfarin } \\
\hline Gjennomsnittsalder i meldingene & 76 & 75 & 80 & 79 \\
\hline $\begin{array}{l}\text { Gjennomsnittsalder for døde i } \\
\text { meldingene }\end{array}$ & 79 & 81 & 81 & 80 \\
\hline $\begin{array}{l}\text { Andel døde/1 000 brukere av } \\
\text { antikoagulantia' }\end{array}$ & 0,7 & 1,1 & 0,9 & 0,6 \\
\hline De vanligste dødsårsakene i antall: & & & & \\
\hline Hjerneblødning & 5 & 21 & 8 & 56 \\
\hline Gastrointestinalblødning & 4 & 3 & 0 & 6 \\
\hline Hjerneinfarkt & 2 & 3 & 1 & 0 \\
\hline Tid for dødsfallet: & & & & \\
\hline Dødsfall første måned (\%) & 0 & 21 & 22 & 0 \\
\hline Dødsfall første 6 md (\%) & 29 & 53 & 78 & 13 \\
\hline
\end{tabular}

${ }^{1}$ Data er hentet fra Reseptregisteret, $\emptyset$ vrige data er hentet fra bivirkningsdatabasen

Andel bivirkningsmeldinger klassifisert som alvorlige var $97 \%$ for warfarin, 82 \% for apiksaban, 76 \% for rivaroksaban og 74 \% for dabigatran. I begynnelsen ble både alvorlige og mindre alvorlige hendelser rapportert for direktevirkende orale antikoagulasjonsmidler. Etter hvert ble i økende grad kun alvorlige hendelser meldt. For warfarin ble det i hele perioden hovedsakelig meldt alvorlige bivirkninger.

\section{DØDELIG UTFALL}

Andel bivirkningmeldinger med dødelig utfall var 50 \% for warfarin, $38 \%$ for apiksaban, $19 \%$ for dabigatran og $17 \%$ for rivaroksaban. Antallet dødsfall per 1 ooo brukere av 
antikoagulantia var høyest for rivaroksaban, med synkende tall for henholdsvis apiksaban, dabigatran og warfarin. De vanligste dødsårsakene angitt i meldingene var hjerneblødning, gastrointestinalblødning og hjerneinfarkt. Tallene er ikke justert for antall brukere. De fleste dødsfallene skjedde i løpet av det første halvåret etter behandlingsoppstart, en mindre andel av pasientene døde i første behandlingsmåned ( $\left.\operatorname{tab}_{3}\right)$.

\section{KOMORBIDITET}

Pasientene som døde, hadde større grad av komorbiditet, som hypertensjon, hjertesykdom eller nyresvikt, enn de som overlevde. Dette gjeldt brukere både av direktevirkende orale antikoagulasjonsmidler og av warfarin (tab 4).

\section{Tabell 4}

Andelen av pasienter med oppgitt hypertensjon, hjertesykdom og redusert nyrefunksjon i gruppen for direktevirkende orale antikoagulasjonsmidler (DOAK) og i gruppen for warfarin. Tallene i parentes er absolutte tall for de som overlevde og de som døde. Kilde: Bivirkningsdatabasen

\begin{tabular}{|lcrr|}
\hline & \multicolumn{3}{c|}{ Hypertensjon Hjertesykdom Nyresvikt } \\
\hline DOAK, overlevende $(\%)(\mathrm{n}=231)$ & $34(78)$ & $16(36)$ & $8(18)$ \\
\hline DOAK, døde $(\%)(\mathrm{n}=58)$ & $40(23)$ & $28(16)$ & $19(11)$ \\
\hline Warfarin, overlevende $(\%)(\mathrm{n}=59)$ & $29(17)$ & $25(15)$ & $5(3)$ \\
\hline Warfarin, døde $(\%)(\mathrm{n}=59)$ & $34(20)$ & $32(19)$ & $8(5)$ \\
\hline
\end{tabular}

\section{Diskusjon}

$\emptyset$ kningen i meldte bivirkninger ved direktevirkende orale antikoagulasjonsmidler og warfarin i perioden skyldtes trolig både $ø$ kt forskrivning av legemidlene og det at Legemiddelverket/RELIS spesielt oppfordret til å rapportere bivirkninger ved antikoagulantia (13).

Det er kjent at langt fra alle bivirkninger meldes og at det ikke er tilfeldig hvilke hendelser som blir rapportert. I vårt materiale var det flere meldinger for direktevirkende orale antikoagulasjonsmidler (relatert til antall brukere) enn for warfarin. Dette betyr imidlertid ikke at direktevirkende orale antikoagulasjonsmidler gir flere bivirkninger enn warfarin. Årsaken kan være at det er større interesse for å rapportere bivirkninger ved nye legemidler. Når et legemiddel er kjent, blir mindre alvorlige bivirkninger sjeldnere meldt $(14,15)$. I en svensk studie med warfarin ble bare $14 \%$ av de alvorlige blødningene rapportert (16).

\section{BIVIRKNINGSFOREKOMST FOR HVERT PREPARAT}

De hyppigst meldte bivirkningene i vår studie (tab 2) samsvarer godt med det som er sett $\mathrm{i}$ andre studier $(17,18)$. Bivirkningene er oppgitt i absolutte tall. Siden det ikke er justert for antall brukere og underrapportering, kan tallene ikke brukes til å estimere frekvens av bivirkninger. Antall meldte bivirkninger for hvert direktevirkende orale antikoagulasjonsmiddel i studien varierer. Rivaroksaban har høyest forekomst, også når tallet korrigeres for antall brukere. I en nylig publisert norsk studie synes det som at rivaroksaban ga høyere risiko for blødninger enn dabigatran og apiksaban (19), noe som også er sett i en svensk studie (17). I vår studie ble det fanget opp enkelte mulige bivirkninger, som håravfall og ulike bivirkninger fra sentralnervesystemet, som ikke var angitt i preparatomtalene, men som siden er blitt undersøkt videre av legemiddelmyndighetene.

\section{TID FØR FØRSTE BIVIRKNING}

Majoriteten av bivirkningene for direktevirkende orale antikoagulasjonsmidler oppsto $\mathrm{i}$ 
løpet av de første seks månedene av behandlingen, mens en mindre andel oppsto i den første måneden. Tilsvarende tall ved bruk av warfarin er små, fordi det var få nyoppstartede warfarinbrukere i vårt materiale. Blant annet fordi det i en tidligere norsk studie ble vist at de fleste meldte blødningsbivirkninger forårsaket av warfarin oppsto kort tid (i løpet av den første måneden) etter behandlingsstart (10), har noen tenkt at dette generelt kan gjelde for antikoagulantia. Ut ifra observasjoner i vårt materiale kan det se ut som om bivirkninger ved bruk av direktevirkende orale antikoagulasjonsmidler i større grad oppstår når pasienten har brukt legemidlet i noe lengre tid. Det er viktig å ta hensyn til dette ved behandling og oppfølging av pasienter med antikoagulasjonsbehandling, særlig siden pasienter nå i økende grad behandles med direktevirkende orale antikoagulasjonsmidler istedenfor warfarin (19).

\section{ALDER OG KJØNN}

Det var generelt høyere andel menn i bivirkningsmeldingene. Dette kan skyldes at flere menn enn kvinner har atrieflimmer og behandles med antikoagulantia (tab 1) (20), og at bivirkningstallene følger bruken. At det for rivaroksaban var en noe lavere andel menn, var antagelig tilfeldig. Vi fant også at de fleste pasientene i bivirkningsmeldingene var over 70 $\operatorname{år}\left(\operatorname{tab}_{3}\right)$. Eldre pasienter er ofte sykere og har derfor større risiko for bivirkninger, også når de behandles med antikoagulantia (21).

\section{ANDEL AV ALVORLIGE BIVIRKNINGER}

Ut over i studieperioden $\emptyset$ kte andelen alvorlige bivirkningsmeldinger for rivaroksaban. Dette kan forklares med at legemidlet ble bedre kjent for klinikere, og at de da lot være å melde de mindre alvorlige bivirkningene. Meldemønsteret for rivaroksaban nærmet seg meldemønsteret for warfarin, der det nesten utelukkende er alvorlige hendelser som blir meldt.

\section{BIVIRKNINGER MED FATALT UTFALL}

Majoriteten av dødsfallene i vårt materiale var forårsaket av hjerneblødninger. Dette stemmer med det som ble sett i de pivotale studiene (1-3) og i en senere epidemiologisk studie (17). De fleste pasientene som døde, hadde brukt antikoagulantia i mer enn én måned, noe som er viktig å ta med i betraktningen når det gjelder oppfølging av disse pasientene.

\section{KOMORBIDITET}

Vi fant at det var høyere komorbiditet (blant annet hypertensjon, hjertesykdom og nyresvikt) hos pasientene som døde enn hos dem som overlevde. I en studie ble lav kroppsvekt, endret sammensetning av fett og muskler, redusert nyrefunksjon, høy komorbiditet, demens og fallrisiko angitt som noen predisponerende faktorer for bivirkninger ved bruk av direktevirkende orale antikoagulasjonsmidler (21). En annen studie viste at blant annet redusert nyrefunksjon predikerte høy risiko for blødning (17). Dabigatran er kontraindisert hos pasienter med alvorlig nedsatt nyrefunksjon (kreatininclearance $<30 \mathrm{ml} / \mathrm{min}$ ) fordi dette medfører høye serumkonsentrasjoner som gir høy blødningsrisiko (22). Vurdering av pasientens nyrefunksjon er også viktig ved behandling med apiksaban og rivaroksaban, som ikke anbefales hos pasienter med kreatininclearance under $15 \mathrm{ml} / \mathrm{min}(5)$.

\section{STUDIENS BEGRENSNINGER}

Underrapportering er et kjent problem for spontanrapporterte bivirkningsmeldinger, og vårt materiale er forholdsvis lite. Funnene i studien er derfor ikke egnet til å sammenligne bivirkningsforekomst mellom warfarin og direktevirkende orale antikoagulasjonsmidler eller til å trekke konklusjoner med hensyn til bivirkningsfrekvens og type bivirkninger ved de ulike midlene. 


\section{Konklusjon}

Bivirkningsprofilene til direktevirkende orale antikoagulasjonsmidler er fremdeles ikke fullstendig klarlagt. All behandling med antikoagulantia bør gjøres etter grundig individuell vurdering av hver enkelt pasient. Særlig bør de eldste behandles på streng indikasjon og med tett oppfølging av eventuelle bivirkninger. Nedjustering av dosen kan vurderes ved redusert nyrefunksjon, komorbiditet og interaksjonsrisiko med andre legemidler. Det er i tillegg viktig å lytte til det pasientene opplever av ubehag og mulige bivirkninger etter oppstart av legemidlene. I vårt materiale så vi at mange av bivirkningene, også de fatale, kom etter flere måneders bruk av legemidlene.

\section{HOVEDBUDSKAP}

Bivirkninger, også alvorlige, oppsto ved bruk av både warfarin og de nye direktevirkende orale antikoagulasjonsmidlene (dabigatran, rivaroksaban og apiksaban)

Pasienter med komorbiditet, høy alder eller som brukte andre legemidler som kan gi blødning, hadde $ø$ kt risiko for alvorlige hendelser og $\mathrm{d} ø \mathrm{~d}$

All behandling med antikoagulantia krever grundig og regelmessig oppfølging

\section{LITTERATUR:}

1. Connolly SJ, Ezekowitz MD, Yusuf S et al. Dabigatran versus warfarin in patients with atrial fibrillation. N Engl J Med 2009;361: 1139 - 51. [PubMed][CrossRef]

2. Granger CB, Alexander JH, McMurray JJ et al. Apixaban versus warfarin in patients with atrial fibrillation. N Engl J Med 2011;365: 981 - 92. [PubMed][CrossRef]

3. Patel MR, Mahaffey KW, Garg J et al. Rivaroxaban versus warfarin in nonvalvular atrial fibrillation. N Engl J Med 2011; 365: 883 - 91. [PubMed][CrossRef]

4. Gómez-Outes A, Suárez-Gea ML, Lecumberri R et al. Direct oral anticoagulants in the treatment of venous thromboembolism, with a focus on patients with pulmonary embolism: an evidence-based review. Vasc Health Risk Manag 2014; 10: 627-39. [PubMed][CrossRef]

5. Informasjon om warfarin og de direkte virkende perorale antikoagulasjonsmidlene dabigatran, rivaroksaban og apixaban. Nasjonal rådgivende spesialistgruppe innen antikoagulasjon. Oslo: Helsedirektoratet, 2015.

https://helsedirektoratet.no/Lists/Publikasjoner/Attachments/433/Informasjon-om-warfarin-og-de-per orale-antikoagulasjonsmidlene-dabigatran-rivaroksaban-og-apixaban-IS-205o-Fullversjon.pdf (13.1.2016).

6. Guideline on good pharmacovigilance practices (GVP) - Module VI - Management and reporting of adverse reactions to medicinal products (Rev 1). European Medicines Agency, 2014.

http://www.ema.europa.eu/docs/en_GB/document_library/Scientific_guideline/2014/o9/WC50017240 2.pdf(2.5.2018)

7. Harg P, Lislevand H, Buajordet I et al. Bivirkningsrapportering og legemiddelovervåking. Tidsskr Nor Lægeforen 2003; 123:331 - 2. [PubMed]

8. Myhr K. G5 Bivirkninger og legemiddelovervåking. Norsk Legemiddelhåndbok 2016. http://legemiddelhandboka.no/Generelle/93635(25.1.2017).

9. Bivirkningsrapport for 2011. Oslo: Statens Legemiddelverk, 2012. https://legemiddelverket.no/Documents/Bivirkninger\%20og\%2osikkerhet/Rapporter\%2oog\%2ooversik ter/\%C3\%85rsrapporter/\%C3\%85rsrapport\%2oBivirkninger\%202011.pdf(9.2.2018).

10. Breen AB, Vaskinn TE, Reikvam A et al. Warfarinbehandling og blødninger. Tidsskr Nor Lægeforen 2003; 123: 1835-7. [PubMed]

11. World Health Organization - Uppsala Monitoring Centre. Common concepts and terms in pharmacovigilance. 
https://www.who-umc.org/safer-use-of-medicines/safer-use-of-medicines-the-basics/common-concepts -and-terms/(2.5.2018).

12. Urbaniak AM, Strøm BO, Krontveit R et al. Prescription patterns of non-vitamin k oral anticoagulants across indications and factors associated with their increased prescribing in atrial fibrillation between 2012-2015: a study from the Norwegian prescription database. Drugs Aging 2017; 34: 635 - 45. [PubMed][CrossRef]

13. Stenberg-Nilsen H. Tilleggsskjema - bivirkninger av antikoagulantia.

https://relis.no/Bivirkninger/Nytt_om_bivirkninger/2013/Tilleggsskjema_bivirkninger_av_antikoagu lantia/(23.3.2017).

14. Bäckström M, Mjörndal T, Dahlqvist R et al. Attitudes to reporting adverse drug reactions in northern Sweden. Eur J Clin Pharmacol 20oo; 56: 729-32. [PubMed][CrossRef]

15. Pillans PI. Clinical perspectives in drug safety and adverse drug reactions. Expert Rev Clin Pharmacol 2008; 1: 695-705. [PubMed][CrossRef]

16. Bäckström M, Mjörndal T, Dahlqvist R. Under-reporting of serious adverse drug reactions in Sweden. Pharmacoepidemiol Drug Saf 2004; 13: 483 - 7. [PubMed][CrossRef]

17. Al-Khalili F, Lindström C, Benson L. The safety and persistence of non-vitamin-K-antagonist oral anticoagulants in atrial fibrillation patients treated in a well structured atrial fibrillation clinic. Curr Med Res Opin 2016; 32: 779 - 85. [PubMed][CrossRef]

18. Saraf K, Morris PD, Garg P et al. Non-vitamin K antagonist oral anticoagulants (NOACs): clinical evidence and therapeutic considerations. Postgrad Med J 2014; 90: 520 - 8. [PubMed][CrossRef]

19. Halvorsen S, Ghanima W, Fride Tvete I et al. A nationwide registry study to compare bleeding rates in patients with atrial fibrillation being prescribed oral anticoagulants. Eur Heart J Cardiovasc Pharmacother 2017; 3: 28 -36. [PubMed][CrossRef]

20. Granada J, Uribe W, Chyou PH et al. Incidence and predictors of atrial flutter in the general population. J Am Coll Cardiol 2000;36: 2242 - 6. [PubMed][CrossRef]

21. Kundu A, Sardar P, Chatterjee S et al. Minimizing the risk of bleeding with NOACs in the elderly. Drugs Aging 2016; 33: 491 - 500. [PubMed][CrossRef]

22. Moore TJ, Cohen MR, Mattison DR. Dabigatran, bleeding, and the regulators. BMJ 2014;349: g4517.

[PubMed][CrossRef]

Publisert: 21. august 2018. Tidsskr Nor Legeforen. DOI: 10.4045/tidsskr.17.0706

Mottatt 17.8.2017, første revisjon innsendt 17.4.2018, godkjent 2.5.2018.

(C) Tidsskrift for Den norske legeforening 2020. Lastet ned fra tidsskriftet.no 